Motrivivência Ano XXIII, No 36, P. 63-74 Jun./2011

doi: 10.5007/2175-8042.2011v23n36p63

\title{
MOVIMENTO HUMANO, ONTOLOGIA DO SER SOCIAL E EDUCAÇÃO FÍSICA
}

Vidalcir Ortigara'

\section{RESUMO}

O objetivo deste artigo é apresentar a possibilidade de cognoscibilidade do movimento como atividade específica do humano, constituído nas relações postas pela realidade social. O foco é o agir humano no complexo de relações que o institui e constitui. A abordagem é a da perspectiva ontológica histórico-materialista. Primeiramente procuramos contextualizar parte da trajetória que nos conduziu à problemática para, em seguida, mostrarmos como as abordagens críticas sobre movimento e corpo na área de Educação Física carecem de uma reflexão ontológica sobre o tema, causando, a nosso ver, limites no alcance de tal crítica. Apontamos, então, os estudos lukacsianos da ontologia do ser social como uma das possibilidades de avanço na compreensão da especificidade do agir humano manifesto nos temas da Educação Física.

Palavras Chave: Educação Física; movimento humano; ontologia do ser social.

O imprevisto é uma espécie de Deus avulso, Ao que é preciso dar algumas ações de graças;

Pode ter voto decisivo na Assembléia dos acontecimentos.

Machado de Assis

Toda discussão seja ela filosófica, religiosa, artística, cultural, etc. tem como pressuposto um determinado contexto real, o qual determina as condições e a posição inicial dos debatedores diante da problemática que se apresenta. Este artigo não foge à regra. Seu objetivo

1 Licenciado em Educação Física. Doutor em Educação. Professor do Programa de Pós-graduação em Educação da Universidade do Extremo Sul Catarinense- PPGE-UNESC.

Contato: vidalcir@hotmail.com 
é o de apresentar a possibilidade de cognoscibilidade do movimento como atividade específica do humano, constituído nas relações postas pela realidade social. Embora a temática tenha surgido com referência nas diversas manifestações das atividades presentes na prática pedagógica da Educação Física - esporte, dança, ginástica, jogos, brincadeiras, entre outras - o enfoque aqui estabelecido busca ampliá-la. O foco é o agir humano no complexo de relações que o institui e constitui. A abordagem é a da perspectiva ontológica históricomaterialista.

Primeiramente procuramos contextualizar parte da trajetória que nos conduziu à problemática para, em seguida, mostrarmos como as abordagens críticas sobre movimento e corpo na área de Educação Física carecem de uma reflexão ontológica sobre o tema, causando, a nosso ver, limites no alcance de tal crítica. Apontamos, então, os estudos lukacsianos da ontologia do ser social como uma das possibilidades de avanço na compreensão da especificidade do agir humano manifesto nos temas da Educação Física.

A especificidade do movimento humano chamou-nos atenção ao mesmo tempo em que buscávamos apreender a condição específica do humano definida, em primeiro lugar, por ser eminentemente social e que necessita apropriar-se da produção histórica para assegurar a satisfação de suas necessidades de sobrevivência. Em outras palavras, sua condição ontológica, isto é, ser social. Esta questão permanece confusa se não captarmos o real significado de tal condição.

Comumente, em Educação Física e nas áreas correlatas, o que se observa é a tentativa de compreender o modo e as formas do processo de desenvolvimento humano a partir das manifestações práticas imediatamente dadas ou do conhecimento previamente estabelecido $^{2}$, que nem sempre leva em consideração a real constituição do ser social. O "jogar luz" sobre essa problemática é imprescindível para compreendermos qual o sentido e o significado que o movimento humano, como objeto de estudo e atuação da Educação Física escolar, possui no processo de formação humana. Nossa atenção volta-se para o próprio sentido da existência humana e, nessas circunstâncias, para o como se constrói o significado do movimento que lhe é próprio, mais especificamente no processo de

2 Duarte (2003), no primeiro capítulo do livro "Sociedade do Conhecimento ou Sociedade das Ilusões" analisa esta questão em relação às pedagogias do "aprender a aprender". 
Ano XXIII, n 36, junho/2011

formação desenvolvido na atividade escolar.

Se por um lado essas indagações possuem um caráter genéri$\mathrm{CO}$, pois questionam o significado do ser humano, por outro se revelavam bastante restritas, uma vez que enfocam a especificidade de seu movimento a partir das reflexões da prática pedagógica. As dificuldades para aprofundar esta reflexão, principalmente no contexto das discussões no campo da Educação Física, são muitas e variadas, mas compreender o ser humano implica apreender sua formação como genericidade, isto é, o caráter que o distingue dos outros animais, o seu ser social. Só assim é possível apreender também seu movimento, uma vez que esse se especifica na própria constituição do ser social.

Muitos autores buscam estabelecer esta genericidade, quando é admitida, na linguagem (Habermas) o que nos parece ser insuficiente, mesmo que esta seja uma importante característica da especificidade do ser social. Ela não é suficiente, em primeiro lugar, porque tal abordagem tem como pressuposto uma concepção de linguagem que lhe atribui um papel fundante, acepção que falseia o processo de constituição da especificidade do ser social, pois o desvia dos concretos complexos históricosociais mediadores de suas relações. Segundo, porque a linguagem não se caracteriza por ser um a priori do processo de desenvolvimento e aprendizagem. Ao contrário, desenvolve-se no processo histórico de constituição do ser social.

Ao verificarmos o processo histórico de constituição do ser social estas questões se esclarecem. Sobre este processo, LEONTIEV (apud SHUARE, 1990, p. 22) afirma que "Cada homem aprende a sê-lo. Para viver na sociedade não é suficiente o que a natureza lhe dá ao nascer. Ele deve dominar, ademais, o que tem sido logrado no desenvolvimento histórico da sociedade humana." Reconhecer a determinação do processo de efetivação do ser humano como social por excelência não significa considerá-lo objeto passivo da influência social. "O homem nunca é só objeto; é, ao mesmo tempo, o sujeito das relações sociais; sendo o produto da sociedade, é também quem a produz" (SHUARE, 1990, p. 22). Nesse mesmo sentido, BHASKAR (2000, f. 9) afirma que homens e mulheres são condicionados pelas estruturas sociais em que estão inseridos, ao mesmo tempo em que são os produtores dessas mesmas estruturas. "É importante salientar que a reprodução e/ou transformação da sociedade, embora na maioria dos casos seja inconscientemente alcançada é, não obstante e ainda, um feito, uma realização hábil de sujeitos ativos, 
e não uma conseqüência mecânica de condições antecedentes."

LEONTIEV ([198-]), na obra O Desenvolvimento do Psiquismo, ao discutir o que diferencia a formação do indivíduo como processo de apropriação ativa e adaptação ao meio - a ontogênese animal -, estabelece a distinção entre espécie humana e gênero humano. Espécie humana refere-se à formação determinada pelo biológico, à "hominização", enquanto o gênero humano ao processo de humanização, em que o ser humano para se constituir como ser necessita apropriar-se de aptidões e funções humanas engendradas pelo conjunto das relações sociais.

VYGOTSKY (1994, p. 74), para explicitar esse processo ativo de apropriação, utiliza o conceito de internalização, referindo-se à "... reconstrução interna de uma operação externa". Tal conceito interessanos de perto, pois, quer nos parecer, contribui e ilumina a questão do movimento. Para Vygotsky o processo de internalização constitui-se em uma série de transformações: a) uma operação que inicialmente representa uma atividade externa, produzida socialmente, é reconstruída e começa a ocorrer internamente; b) um processo interpessoal é transformado em um processo intrapessoal; c) a transformação de um processo interpessoal em um processo intrapessoal é resultado de uma longa série de eventos ocorridos ao longo do desenvolvimento. Isso se torna mais claro ao analisarmos o exemplo utilizado pelo autor, no qual explicita o desenvolvimento do gesto de apontar.

A criança, por volta dos sete ou oito meses de idade, tenta pegar um objeto colocado além de seu alcance com as mãos esticadas em sua direção, com movimento dos dedos que lembra o pegar. Sua tentativa malsucedida de pegar engendra uma reação; não do objeto, mas de uma outra pessoa.

Consequentemente, o significado primário daquele movimento malsucedido de pegar é estabelecido por outros. Somente mais tarde, quando a criança pode associar o seu movimento à situação objetiva como um todo, é que ela, de fato, começa a compreender esse movimento como gesto de apontar. Nesse momento, ocorre uma mudança naquela função do movimento: de um movimento orientado pelo objeto, torna-se um movimento dirigido para uma outra pessoa, um meio de estabelecer relações. O movimento de pegar transforma-se no ato de apontar [grifo no original]. (VYGOTSKY, 1994, p. 74 )

Vygotsky expressa, com esse exemplo, como o desenvolvimento social não só do movimento, mas do próprio ser social, necessita produzir 
e se reproduzir mediante sua própria atividade. SHUARE (1990, p. 21), ao discutir o conceito de atividade na psicologia histórico-cultural soviética, afirma que quando se considera a atividade uma unidade orgânica das formas sensorial-prática e teórica do ser humano, supera-se a ruptura entre teoria e prática e afirma-se, aí, na atividade, a essência genérica do ser humano. "O caráter integral da atividade se sintetiza no conceito de prática que inclui as múltiplas formas da atividade humana e põe o trabaIho em sua base, como forma superior de manifestação. A atividade não só determina a essência do homem, senão que, sendo a verdadeira substância da cultura do mundo humano, cria o homem mesmo."

Com essa discussão aproximamo-nos do ponto central de nossa discussão. Questionamos as proposições pedagógicas da Educação Física brasileira e as dificuldades que encontram em expor as diferenças existentes entre o andar, o correr, o saltar, o pular de homens e mulheres e o de outros animais. ${ }^{3}$ Qual o sentido e o significado do movimento humano como elemento constitutivo da atividade humana, vale dizer, qual sua especificidade, se é que ele a possui? Admitindo-se que a realização do movimento por homens e muIheres, desde os primeiros períodos de suas vidas, diferencia-se intensiva e extensivamente da realização do movimento dos animais, é possível levantarmos algumas interrogações: essa diferenciação ocorre naturalmente, unicamente por força da natureza, é um constructo cultural, ou seria necessária outra possibilidade de entendimento? Como explicar a relação entre o cultural e o natural? No contexto da sociabilidade capitalista, como orientar as reflexões relacionadas às práticas pedagógicas da Educação Física escolar? A ação que a área exerce poderia levar à "emancipação" (KUNZ, 1991, 1994) ou seria uma das forças auxiliares na "superação" (COLETIVO DE AUTORES, ${ }^{4}$ 1992) ${ }^{5}$ do modelo social vigente? ${ }^{6}$

3 Muito embora parte da produção teórica da Educação Física brasileira nem mesmo se coloca essa questão, considerando o andar, o correr, o saltar, o pular como atividade "natural" de homens e mulheres, igualando-os aos animais.

4 É corrente na área de Educação Física referenciar a obra dessa forma. O livro foi escrito por: Carmem Lúcia Soares, Celi Nelza Zülke Taffarel, Lino Castellani Filho, Maria Elizabeth Medicis Pinto Varjal, Micheli Ortega Escobar e Valter Bracht.

5 Estas são as indicações das duas principais tendências teórico-pedagógicas do campo crítico, "contra hegemônico" (GRAMSCI, apud AVILA, 2000), da Educação Física brasileira: a críticoemancipatória e a crítico-superadora.

6 Outras questões podem ser apresentadas, como por exemplo: qual o trabalho a ser realizado para que se tematize a questão de gênero masculino e feminino no espaço escolar? Como deve ser a formação dos professores de Educação Física? 
As abordagens críticas da Educação Física brasileira avançam significativamente em suas discussões do movimento humano, porém há problemas de compressão de sua especificidade e do próprio corpo humano como locus da manifestação de sua atividade, advindos da ausência de reflexão sobre a real constituição ontológica do ser humano como ser social. Tal ausência deixa muitas das questões elencadas sem respostas satisfatórias. Não pretendemos estabelecer aqui o cabedal de respostas que elas merecem, mas unicamente apontar uma possibilidade para a busca de tais respostas.

Os enfoques sobre o corpo e o movimento humano que a Educação Física tem privilegiado não buscam explanar sua real constituição como específicos do ser social. A explicitação dessa realidade exige a compreensão da condição originária de homens e mulheres como seres que produzem e reproduzem as suas próprias condições de existência. Nessa atividade produzem a si mesmos e, no interior desse processo, produzem e reproduzem sua corporalidade e seu movimento. Sob essa exigência, afirmamos a necessidade de um enfoque que considere a sua existência concreta, isto é, a abordagem ontológica do ser social.

\section{Uma possibilidade ontológica}

Para estabelecer esse novo enfoque é necessário avançar no entendimento do processo de constituição do ser social, no processo ontológico da determinação do humano de homens e mulheres, possibilitado pelo estudo da obra do filósofo húngaro György LUKÁCS (1981), Per L'Ontologia dell'Essere Sociale, a qual se constitui no principal aporte teórico deste trabalho. LUKÁCS nasceu em Budapest no dia 13 de abril de 1885 e morreu na mesma cidade em 04 de junho de 1971. Foi um dos principais filósofos do século $X X$, com uma trajetória "tão longa e tão acidentada" (KONDER, 1980, p. 15) que se torna impossível, dado o caráter deste estudo, caracterizá-la detalhadamente.

Alguns estudiosos estabelecem seu pensamento em três grandes fases. ${ }^{7}$ A primeira compreenderia os seus primeiros anos de elaboração, quando ainda participava do grupo junto a Weber e

7 Outros autores estabelecem duas fases, como OLDRINI (1989): a primeira iria até a década de 20 com seu auge na obra História e Consciência de Classe e a segunda iniciaria no ano de 1930, quando, por ocasião de sua ida a Moscou, entra em contato com os Cadernos Filosóficos de LENIN e os Manuscritos de MARX. 
Simmel. A segunda fase seria basicamente caracterizada pela obra História e consciência de classe, de 1923, em que teria realizado uma interpretação hegeliana do marxismo, como aliás o próprio LUKÁCS reconhece em Pensiero Vissuto: Autobiografia in forma di dialogo (1983). A terceira iniciarse-ia na década de 30 quando, por ocasião de seu exílio em Moscou, teve a oportunidade de ler os Manuscritos Econômico-filosóficos de MARX (1993), até então inéditos, ${ }^{8}$ encetando a crítica à ortodoxia dos conceitos marxistas, relacionada diretamente com as exigências concretas que se faziam prementes na Hungria e em todo o Leste Europeu sob o domínio do stalinismo.

Produziu uma extensa obra sobre a Estética e, posteriormente, passou a preocupar-se com as questões da ética que, segundo TERTULIAN (1990), já faziam parte de suas intenções ainda quando escrevia sobre a estética. ${ }^{9}$ Todavia, não concretizou seu desejo, vindo a falecer antes disso. Escreveu, no entanto, uma introdução - de quase duas mil páginas - à obra que pretendia realizar, publicada postumamente com o título de Ontologia do Ser social.
Não contente com a forma tomada pelos manuscritos, onde os temas são apresentados em capítulos, redigiu Prolegômenos à Ontologia do Ser Social, que passou a ser considerada como parte da obra da Ontologia. Na Ontologia do Ser Social retoma a questão ontológica escrevendo capítulos sobre o neopositivismo, Hegel, Hartmann e Marx, na primeira parte, e sobre as principais categorias do marxismo: trabalho, reprodução social, ideologia e estranhamento, na segunda. Nas palavras de TERTULIAN (1996, f. 1):

Em uma carta datada de 10 de maio de 1960, Georg Lukács anunciava a seu amigo Ernst Fischer, a conclusão de A Estética (efetivamente, a primeira parte de um conjunto que deveria comportar três) e a sua intenção de começar sem demora a elaboração de A Ética. (...) Nos meses que se seguiram a esta carta, meses de intensa reflexão, ele chega à conclusão de que A Ética devia ser precedida de uma introdução, onde seriam examinados os componentes fundamentais e a estrutura da vida social.

8 Os Manuscritos Econômico-filosóficos de Marx foram publicados pela primeira vez em 1932, em Moscou.

9 TERTULIAN (1996) explica que na realidade Lukács só concluiu a primeira parte, de três previstas, da obra Estética, passando à redação do texto que serviria de introdução à estética, ou seja, a Ontologia. 
Neste trabalho merece atenção principalmente à última obra, incluindo os Prolegômenos. Interessa-nos, mais especificamente, a discussão que o autor realiza acerca do gênero humano e da categoria trabalho como fundante, como medium no salto da genericidade muda, isto é, o gênero orgânico - o ser da natureza - para a genericidade humana, o gênero humano - o ser social. Lukács busca explicitar uma teoria que atenda às diferenças entre os seres para caracterizar o específico do ser social. Como assinala TERTULIAN (1996, f. 5), "Lukács se propõe a esboçar na sua Ontologia do Ser Social uma teoria dos níveis do ser, da sua estratificação progressiva (natureza inorgânica, natureza biológica, ser social), com o objetivo principal de fixar as categorias constitutivas do ser social na sua especificidade irredutível." Com uma visão ontológica profunda, apresenta o trabalho como medium do "salto" do ser orgânico (natural) ao ser social (humano) no processo de constituição da genericidade especificamente humana.

LUKÁCS (1981), ao discutir a especificidade do ser social, afirma que existem três grandes espécies de ser: o ser inorgânico, o ser orgânico e o ser social. Chama a atenção para o fato de que não se pode descuidar dos problemas gerais do ser - isto é, a conexão e a diversidade entre as grandes espécies de ser - para se estar em condições de compreender, mesmo que aproximativamente, a essência e a especificidade do ser social. "Sem esta conexão, sem compreender sua dinâmica, não se consegue formular corretamente nenhuma das questões ontológicas autênticas do ser social, e menos ainda se consegue conduzi-las depois em direção a uma solução que corresponda à constituição deste ser." (LUKÁCS, 1990, p. 4)

Nessa dinâmica se explicita o processo de formação humana como ser ativo. Vale dizer: não há um ser humano simplesmente passivo diante dos acontecimentos histórico-culturais com os quais se articula e se relaciona. Pode-se mesmo afirmar que é inconcebível um ser humano totalmente passivo, pois a atividade teleológica positora ${ }^{10}$ transforma a realidade, como a base ontológica de toda práxis humana Ihe é constitutiva.

Em linha de raciocínio semelhante, os estudos de LEONTIEV ([198-]) apontam a compreensão do processo de formação do ser humano em sua especificidade

10 Categoria lukacsiana explicitada no capítulo I do volume dois de Per L'Ontologia dell1Essere Sociale. 
como fundamental para que se possa orientar claramente a ação pedagógica. LUKÁCS (1978) afirma que o processo social - nele incluído a educação - é tão complexo a ponto de ser impossível sua total apreensão, mas que, no campo das possibilidades, pode-se estabelecer uma inter-relação na formação humana, desde que se realize uma aproximação o mais correta possível da realidade concreta.

Destacamos esse aspecto por entender que o complexo educativo é um processo eminentemente social, produto das relações constitutivas do ser humano, uma de suas especificidades mais significativas. Nesse processo encontra-se o movimento humano, que estabelece uma relação dialética - na mediação orgânico e social - com o mundo. Mas é importante compreendermos que o movimento constitutivo do ser humano ao manter sua base orgânica a supera, à medida que não se limita a comportamentos constantes como ocorre com os animais, senão que, em relação aos seres humanos,

...o essencial consiste em torná-los aptos a reagir adequadamente a eventos e situações imprevisíveis, novas, que se apresentarão mais tarde nas suas vidas. Isto significa duas coisas: em primeiro lugar, que a educação do homem - no sentido mais lato - em verdade não é jamais totalmente concluída. A sua vida, se se dá o caso, pode terminar numa sociedade de caráter totalmente distinto, com exigência que são completamente diversas daquelas para as quais a educação - em sentido estrito - o havia preparado. (...) [em segundo], toda sociedade reclama dos próprios membros uma dada massa de conhecimentos, habilidades, comportamentos, etc.; conteúdo, método, duração etc. da educação em sentido estrito são conseqüências das necessidades sociais assim surgidas. (LUKÁCS, 1981, p. 152-153)

A incompreensão da ontológica constituição do ser social conduz a um descolamento e, conseqüentemente, a um achatamento do real complexo de formação e educação de homens e mulheres, do corpo e de seu movimento. O enfoque ontológico sobre o corpo torna-se, assim, indispensável, pois à medida que é negligenciado o entendimento da corporalidade do ser humano padece da mesma deficiência presente em certa compreensão da psicologia históricocultural que, ao não apreender seus fundamentos ontológicos, a reduziu a uma psicologia do humano, possibilitando sua aproximação com 
outras explicações psicológicas do processo de aprendizagem e desenvolvimento, como a piagetiana, por exemplo ${ }^{11}$. O mesmo ocorre em relação às proposições pedagógicas da Educação Física e às reflexões sobre o corpo, em que autores diversos, com explicações até mesmo antagônicas relativas à formação do ser social, são utilizados como complementares. Por essas razões, considero pertinente um estudo das bases ontológicas do ser social para projetar um pouco de luz sobre a concreticidade ontológica do corpo e do movimento como específico da atividade do ser social.

Outra instigante dimensão no caminho de amadurecimento do tema ontologia é o fato de estar diretamente ligado à questão crucial da afirmação ou não da existência do real. Discussão a que se convencionou chamar debate realismo/ anti-realismo. Indagamo-nos: existe um real independente de quem o conhece ou este é tão somente um processo de "construção" no processo de conhecimento? Em outras palavras, conhecer é um processo que se relaciona com o mundo real ou é só um exercício da razão ou expressão cultural que, com isso, estabelece ou cria a realidade?

Tal discussão interessa de perto ao tema aqui abordado e aí, talvez, esteja sua maior atualidade. Senão vejamos: como compreender o movimento humano em sua especificidade sem o entendimento do ser social em sua constituição? Tal entendimento não demandaria a apreensão do contexto históricosocial em que se encontra? Mas seria contexto real, ontologicamente existente, ou apenas produzido pelo ato de conhecimento ou pela cultura e, portanto, só podendo ser considerado na perspectiva epistemológica ou cultural?

É no contexto dessa discussão contemporânea que conclamos para a necessidade desta reflexão, a qual procura mostrar a especificidade da existência humana em sua prioridade ontológica - ser social - e as formas e modos pelos quais ela se constitui em processo histórico. Essa compreensão é básica para os propósitos de uma Educação Física que se atribui a tese de "emancipatória" ou "superadora", pois somente a apreensão da constituição do ser humano como social, e o papel ontologicamente fundante do trabalho neste processo, torna possível o conhecer da realidade do movimento específico da atividade humana no seu desenvolvimento histórico e sua relação com o processo de desenvolvimento e aprendizagem

11 Ver a respeito DUARTE (2000). 
no contexto educacional. Tais características indicam a importância da interlocução com LUKÁCS.

\section{Referências}

AVILA, A. B. As relações entre cultura

e subculturas: circunscrevendo

a cultura corporal. 2000. 101

f. Dissertação (Mestrado em Educação Física) - Universidade Federal de Santa Catarina, Florianópolis.

BHASKAR, R. Uma Teoria Realista da Ciência. Tradução de Rodrigo Leitão. Niterói: UFF, 2000.

COLETIVO DE AUTORES. Metodologia do Ensino de Educação Fïsica. São Paulo: Cortez, 1992.

DUARTE, N. Vigotski e o "aprender a aprender": crítica às apropriações neoliberais e pós-modernas da teoria vigotskiana. Campinas: Autores Associados, 2000.

HABERMAS, J. Conhecimento e interesse. Rio de Janeiro: Zahar, 1982.

KONDER, L. Lukács. Porto Alegre: L\&PM, 1980.

KUNZ, E. Educação Física: Ensino \& Mudança. Ijuí: UNIJUÍ, 1991. - Transformação Didáticopedagógica do Esporte. Ijuí: UNIJUÍ, 1994.

LEONTIEV, A. O Desenvolvimento do Psiquismo. São Paulo: Moraes, [198-].
LUKÁCS, G. Per I'ontologia dell'essere sociale. $v$. 1. liv. 1. Roma: Riuniti, 1976. Introdução a uma Estética Marxista: sobre a categoria da particularidade. Rio de Janeiro: Civilização Brasileira, 1978. - As Bases Ontológicas do Pensamento e da Atividade do Homem. Revista Temas de Ciências Humanas, São Paulo, n. 4, p. 1-18, 1978a.

. Per I'ontologia dell'essere sociale. Roma: Riuniti, 1981. v. 2. liv. 1.

.Pensiero vissuto: autobiografia in forma di dialogo. Roma: Riuniti, 1983.

MARX, K. Manuscritos EconômicoFilosóficos. Lisboa: Edições 70, 1993.

OLDRINI, G. La forma culturale della militanza di Lukács. In: MUSILLAMI, R. (Org.) Filosofia e Prassi: Attualità e rilettura critica di György Lukács e Ernst Bloch. Milano: Diffusioni84, 1989. p. 117-134.

SHUARE, M. La Psicologia Soviética tal como yo la veo. Moscú: Editorial Progresso, 1990.

TERTULIAN, N. Introduzione. In: LUKÁCS, G. Prolegomeni All'Ontologia dell'Essere Sociale: questioni di principio di un'ontologia oggi divenuta possibilie. Milano: Guerini Associati, 1990. 
. Georg Lukács e a reconstrução

da ontologia na filosofia contemporânea. In: Conferência Proferida no Programa de PósGraduação em Educação da
UFCE, 1996, Recife. Trabalho não publicado.

VYGOTSKY, Lev S. A formação social da mente. São Paulo: Martins Fontes, 1994.

\begin{abstract}
The aim of this paper is to present the possibility of knowability of the movement as specific human activity, consisting in relations posed by the social reality. The focus is the human activity in the complex relationships and establishing it is. The approach is the ontological perspective of historical materialism. First try to contextualize part of the path that led us to the problem, then showing how the critical approaches and body movement in the area of Physical Education require an ontological reflection on the subject, causing, in our view, limits the scope of such critical. Aim, then, studies Lukacsian ontology of social being as one of the possibilities for advances in understanding the specificity of human manifest on the issues of Physical Education.
\end{abstract}

Keywords: Physical Education; human movement; ontology of social being.

Recebido: março/2011

Aprovado junho/2011. 